\title{
Correction to: Towards a participatory representative democracy? UK Parish councils and community engagement
}

\author{
Joanie Willett ${ }^{1} \cdot$ Joe Cruxon $^{1}$
}

Published online: 13 July 2018

(C) Springer Nature Limited 2018

\section{Correction to: Br Polit https://doi.org/10.1057/s41293-018-00090-4}

In the original article version unfortunately the second author Joe Cruxon was missing. The original article has been corrected.

The original article can be found online at https://doi.org/10.1057/s41293-018-00090-4.

$\triangle$ Joanie Willett

j.m.a.willett@exeter.ac.uk

1 Department of Politics, University of Exeter, Cornwall Campus, Penryn, UK 